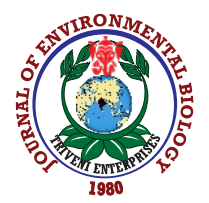

\title{
Estimation of yield loss and relationship of weather parameters on incidence of bakanae disease in rice varieties under shallow low land ecologies of Eastern India
}

\author{
S. Raghu*, G. Guru-Pirasanna-Pandi, M.S. Baite, M.K. Yadav, S.R. Prabhukarthikeyan, U. Keerthana and P.C. Rath \\ Crop Protection Division, ICAR-National Rice Research Institute, Cuttack-753006, India \\ *Corresponding Author Email : raghurm531@gmail.com
}

Received: 03.07.2020

Revised: 03.12.2021

Accepted: 07.03.2021

\begin{abstract}
Aim: To assess yield loss in different rice varieties due to rice bakanae disease and to understand the role of weather parameters on disease incidence and losses.

Methodology: Roving survey and surveillance was carried out for three consecutive years to assess the status of rice bakanae disease among twenty popular rice varieties growing in Eastern India. Field experiment was conducted for three successive years, i.e., 2016, 2017 and 2018 at Cuttack. Highly susceptible variety Pooja was selected for the experiment. Data on disease incidence was collected daily from 10 days after transplanting to harvesting stage and data were recorded at standard meteorological week. Correlation was performed to find the effect of different weather parameters on the incidence of bakanae disease on rice.

Results: Disease being seed borne caused significant reduction in yield and quality. The maximum disease incidence was recorded in Pooja with $18.25,28.50$ and 40.25 per cent in three years. The same variety showed maximum yield loss of 35.26 per cent compared all other varieties. The data on relationship of bakanae disease incidence with weather parameters showed that the rainfall $(-0.444)$ had significant negative correlation during 2018 while $\mathrm{RH}(0.525$ and 0.606$)$ had significant positive correlation during 2017 and 2018.

Interpretation: This study gives some information for formulating breeding programs to develop resistant varieties and management measures for preventing Bakanae disease.

Key words: Bakanae disease, Fusarium fujikuroi, Weather parameters

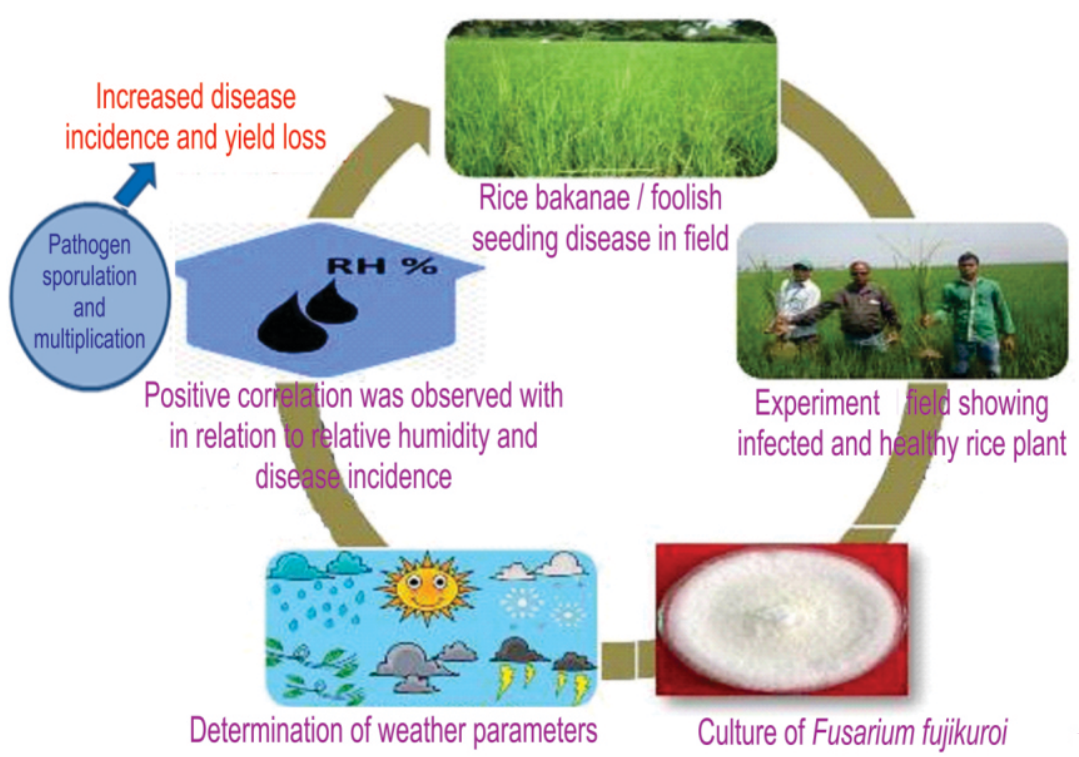

How to cite : Raghu, S., G. Guru-Pirasanna-Pandi, M.S. Baite, M.K. Yadav, S.R. Prabhukarthikeyan, U. Keerthana and P.C. Rath: Estimation of yield loss and relationship of weather parameters on incidence of bakanae disease in rice varieties under shallow low land ecologies of Eastern India. J. Environ. Biol., 42, 995-1001 (2021). 


\section{Introduction}

Rice (Oryza sativa L.) is one of the ancient crop and the most important cereal in terms of ecology and economy. Rice act as the bedrock for food and nutritional security in Asia where half of the global population exists (Khush 2005). The world population is expected to increase by 9.2 billion in the middle of this century and in that situation it will be extremely challenging to meet the food demand all the people with reducing land availability. On the other hand, biotic stress which is one of the major yield limiting factors in rice ecosystem is also increasing at alarming rate (Jena et al., 2018). Among the biotic factors, major diseases like blast, sheath blight, brown spot, tungro and bacterial blight continue to cause more damage under changing climatic scenario and a number of emerging diseases such as bakanae, false smut, early seedling blight, grain discoloration and sheath rot has become a major problem posing serious threat to rice production (Raghu et al., 2018).

India is in the position of exporting long grain basmati rice to middle east countries. But, basmati varieties are facing serious problem of bakanae disease leading to huge yield and quality losses. The disease is caused by fungal pathogen Fusarium fujikuroi, an ascomycetes fungi which can cause $15-26 \%$ yield loss based on varietal susceptibility (Pannu et al., 2012; Sunder et al., 2014; Bashyal et al., 2014; Raghu et al., 2016). North Indian states, especially Punjab, Haryana and Western Uttar Pradesh are facing serious problem of bakanae disease in basmati cultivars, especially PB-1121 which is known for longest cooked grain quality (Fiyaz et al., 2014; Jain et al., 2019). But, the disease has become is a major problem the Eastern and North east India during the last three years. Most of the cultivars growing in this region are highly susceptible to this disease (Raghu et al., 2018). Widely cultivating varieties such as Pooja and Abhishek have been severely affected by bakanae in Odisha and Assam. The pathogen is highly seed borne. When infested seeds are used for sowing, the disease incidence will be more and loss may be ranging from $10-24 \%$. In Punjab state alone, the disease is reported to cause $40 \%$ of the yield loss (Bashyal etal., 2020).

Depending on the type of toxins produced (either fusaric acid, or gibberllic acid) by the pathogen, and prevailing environmental conditions, the pathogen causes different symptoms such as abnormal elongation of seedlings, seedling death, foot rot, light green/lanky seedlings, and chaffy/infertile grains. Bakanae is a monocyclic disease where pathogen Fusarium fujikuroi produces conidia on diseased plants, which easily spread to healthy plants through wind and water. When the pathogen sporulates profusely during flowering and ripening stage, the conidia infect inflorescence and contaminates seeds (Matic et al., 2017). Environmental conditions are one of the three parameters (along with susceptible host and virulent pathogen) which determines disease incidence and establishment, called disease triangle. Different weather parameters play significant role in determining the incidence and geographical distribution of this emerging disease in rice (Luo et al., 1988). All these weather parameters viz, temperature, relative humidity, rainfall, wind speed, evaporation and sun shine hours etc., play a vital role in disease incidence, survival, reproduction and further spread. Unfortunately, the investigation on the role of weather parameters on bakanae disease is scarce or not yet studied in depth. Some workers have reported that, the best suitable temperature for infection and disease development is $27-30^{\circ} \mathrm{C}$ (Burgess et al., 1996). The incidence of bakanae disease reduces when the temperature is reduced (Saremi and Farokhi, 2004).

But, on the basis of observation made in Eastern India, the disease incidence increases with rise in temperature. In Japan, Hino and Furuta (1968) reported an average embryo infection of $8.8 \%$ in July, $8.1 \%$ in August and only $0.03 \%$ in September. Similarly, Bal and Biswas (2018) reported that, crop transplanted in $10^{\text {th }}$ June showed maximum disease incidence $(24.20 \%)$ indicating maximum air temperature had positive correlation with bakanae disease incidence. There is no other study on effect of weather parameters on increased incidence of this serious disease. Therefore a thorough understanding of interaction between weather parameters and bakanae incidence is essential for standardizing management practices. Hence the present investigation was undertaken to study the effect of different weather parameters on incidence of emerging disease bakanae in shallow low land rice ecosystem. A systematic study of how the disease develops under the influence of variable climatic conditions is necessary to manage this emerging disease efficiently.

\section{Materials and Methods}

Roving survey was conducted for three consecutive years to assess the disease incidence and yield loss in 20 popular rice varieties. The disease incidence was recorded using formula given bellow and loss estimation was made by taking observations like number of filled grains, chaffy grains and test weight of seeds. To investigate the relationship of weather parameters and disease, the study was carried out at the Experimental Farm of ICAR-National Rice Research Institute, Cuttack, Odisha, India, during the year 2016, 2017 and 2018 in randomized complete block design with rice variety Pooja (popular and highly susceptible to bakanae disease), which was raised in accordance with recommended agronomic practices without fungicide application. Field preparations were made following standard agronomic practices.

The field was fine tilth and divided into small plots of $5 \times 5$ $\mathrm{mt}^{2}$ with replications allotted using randomization technique. Seeds of highly susceptible variety Pooja were procured with acknowledgement from gene bank of the institute. Artificial seed inoculation technique was followed to raise the diseased seedlings. Most virulent isolate Ff-10 (NCBI Accession number: MK442097) isolated from infected plants of variety Pooja was used for the present study. PDA plates were inoculated with pure culture of pathogen and incubated for $7-10$ days at $28 \pm 1^{\circ} \mathrm{C}$ for full growth. After 10 days, sterilized distilled water was flooded on plates with mycelium and mixed by scraping with a sterilized spatula. The resultant spore suspension was filtered using two 
layers of sterile muslin cloth and adjusted the inoculum concentration to $1 \times 10^{6}$ conidia/ml using heamocytometer. To begin with, seeds of test variety were surface sterilized with $1 \%$ sodium hypochlorite for 2 min followed by 3 washings with sterilized distilled water. For next $24 \mathrm{hr}$, the seeds were soaked in distilled water. Next day, the seeds were challenge inoculated with spore suspension $\left(1 \times 10^{6}\right.$ conidia $\left.\mathrm{ml}^{-1}\right)$ of pathogen for $24 \mathrm{hr}$. Seeds were dried under shade followed by sowing in field and transplanted after 25 days. Per cent disease incidence of bakanae from each plot was collected daily from 10 days after transplanting to harvest stage and data were recorded at standard meteorological week (SMW). The data on weather parameters during the observation period was collected from meteorological observatory located in the institute. The weather parameters studied were daily maximum temperature, minimum temperature, average temperature $\left({ }^{\circ} \mathrm{C}\right)$, relative humidity at 7.00 a.m. and 2.00 p.m. (RH day), bright sun shine hour and wind velocity (kmph). Correlation was analyzed statistically by SPSS 16 statistical software in order to find the effect of different weather parameters on the incidence of bakanae disease on rice. The disease incidence was recorded from each plot in replication by selecting rice plants randomly. The per cent disease incidence (PDI) was calculated by the formula given by Zainudin et al., (2008). In addition to estimating the role of weather parameters, the yield loss and disease incidence among 20 popular rice varities was assessed for three consecutive years.

Statistical analysis: The disease incidence data under the influence of meteorological parameters was pooled and analyzed using SAS 9.3 (SAS 9.3 Institute, Cary, NC) statistical software (www.iasri.res.in/sscnars/).

\section{Results and Discussion}

Among the twenty popular varieties recorded for bakanae disease incidence, Pooja recorded significantly maximum disease incidence compared to all other varieties during three years of study period observation $(18.25,28.50$ and 40.25 percent). Next, the maximum disease incidence was recorded in Abhishek (22.17\%) and Nua sughand dhan-3 (20.92\%), while the least incidence was recorded in Rajalaxmi with $8.75 \%$ disease incidence. From our observations, it is clear that the disease increases season to season irrespective of varieties, raising a concern on its damage and yield losses. The yield loss was also estimated for all three years and it was found that, the maximum yield loss was recorded in Pooja (35.26\%) followed by Abhishek $(26.25 \%)$ and Nua sughand dhan-3 $(25.25 \%)$, whereas, the least yield loss was recorded in Rajalaxmi (10.00\%).

Fig. 1 shows that the disease can cause significant yield reduction in different genotypes. Since disease is seed borne in nature, it may aggravate in successive seasons if infected seeds are used for sowing. Correlation coefficient between bakanae, Fusarium fujikuroi incidence and weather parameters (Table 1) revealed that bakanae had significant positive correlation with relative humidity during the corresponding week for the observed years 2017 and 2018 whereas lag week 1 data showed that rain fall $(-0.444)$ had significant negative correlation during 2018, while relative humidity $(0.525$ and 0.606$)$ had significant positive correlation during 2017 and 2018, respectively. Similarly during lag week 2 data revealed that bakanae had significant positive correlation with relative humidity, whereas significant negative correlation was observed with rainfall. Other important weather parameter, temperature showed non-significant negative correlation with bakanae incidence for all the observed years.

These results indicate that increasing maximum temperature, minimum temperature, wind speed and rain fall has depressing effect on bakanae incidence; whereas relative humidity favored bakanae incidence and survival. Fig. 2A shows that infestation of bakanae, F. fujikuroi started from $2^{\text {nd }}$ standard meteorological week (SMW) during 2016 and the population gradually increased during the successive weeks and reached maximum level at $12^{\text {th }}$ SMW (29\%). Similarly during 2017 and 2018 also YSB appeared (Fig. 2B) on $2^{\text {nd }}$ SMW and the highest peak (30 and $28 \%$ ). recorded at $11^{\text {th }}$ SMW, for the year showed that 2017 and 2018 Data clearly depicts that bakanae incidence only one peek for the observed year (Fig. 2C), indicating weather plays a crucial role in bakanae per cent increase. Bakanae is emerging as a major threat to rice production and productivity. The disease is caused by Fusarium fujikuroi Nirenberg [F. moniliforme (Sheld.), telomorph: Gibberella fujikuroi Sawada, Wollenweber]. The disease is becoming more serious in Asia and other rice growing countries of the world (Singh and Sunder,

Table 1: Correlations coefficient between weather parameters and incidence of bakanae disease

\begin{tabular}{lllllllll}
\hline Year & Week & $\begin{array}{l}\mathrm{T} \operatorname{Max}\left({ }^{\circ} \mathrm{C}\right) \\
\left({ }^{\circ} \mathrm{C}\right)\end{array}$ & $\begin{array}{l}\mathrm{T} \text { Min } \\
\left({ }^{\circ} \mathrm{C}\right)\end{array}$ & $\begin{array}{l}\text { Rainfall } \\
(\mathrm{mm})\end{array}$ & $\begin{array}{l}\mathrm{RH}-\mathrm{I}(\mathrm{7AM}) \\
(\%)\end{array}$ & $\begin{array}{l}\text { RH-II (2PM) } \\
(\%)\end{array}$ & $\begin{array}{l}\text { Wind speed } \\
(\mathbf{k m p h})\end{array}$ & $\begin{array}{l}\text { Bright sunshine } \\
(\mathrm{hrs})\end{array}$ \\
\hline 2016 & Lag week 2 & -0.25 & -0.225 & -0.267 & $0.543^{*}$ & -0.138 & $-0.506^{*}$ & -0.418 \\
2017 & Current Week & 0.159 & 0.168 & 0.318 & $0.527^{*}$ & 0.428 & -0.027 & 0.105 \\
& Lag week 1 & -0.049 & -0.022 & 0.385 & $0.525^{*}$ & 0.382 & -0.269 & 0.16 \\
& Lag week 2 & -0.266 & -0.233 & 0.375 & $0.519^{*}$ & 0.264 & $-0.456^{*}$ & 0.188 \\
2018 & Current Week & 0.093 & 0.07 & -0.408 & $0.451^{*}$ & 0.442 & -0.026 & 0.490 \\
& Lag week 1 & -0.081 & -0.139 & $-0.444^{*}$ & 0.320 & $0.606^{* *}$ & -0.197 & 0.307 \\
& Lag week 2 & -0.235 & -0.351 & $-0.463^{*}$ & 0.148 & $0.688^{* *}$ & -0.347 & 0.120 \\
\hline
\end{tabular}

** - Correlation is significant at the 0.01 level; *- Correlation is significant at the 0.05 level. 


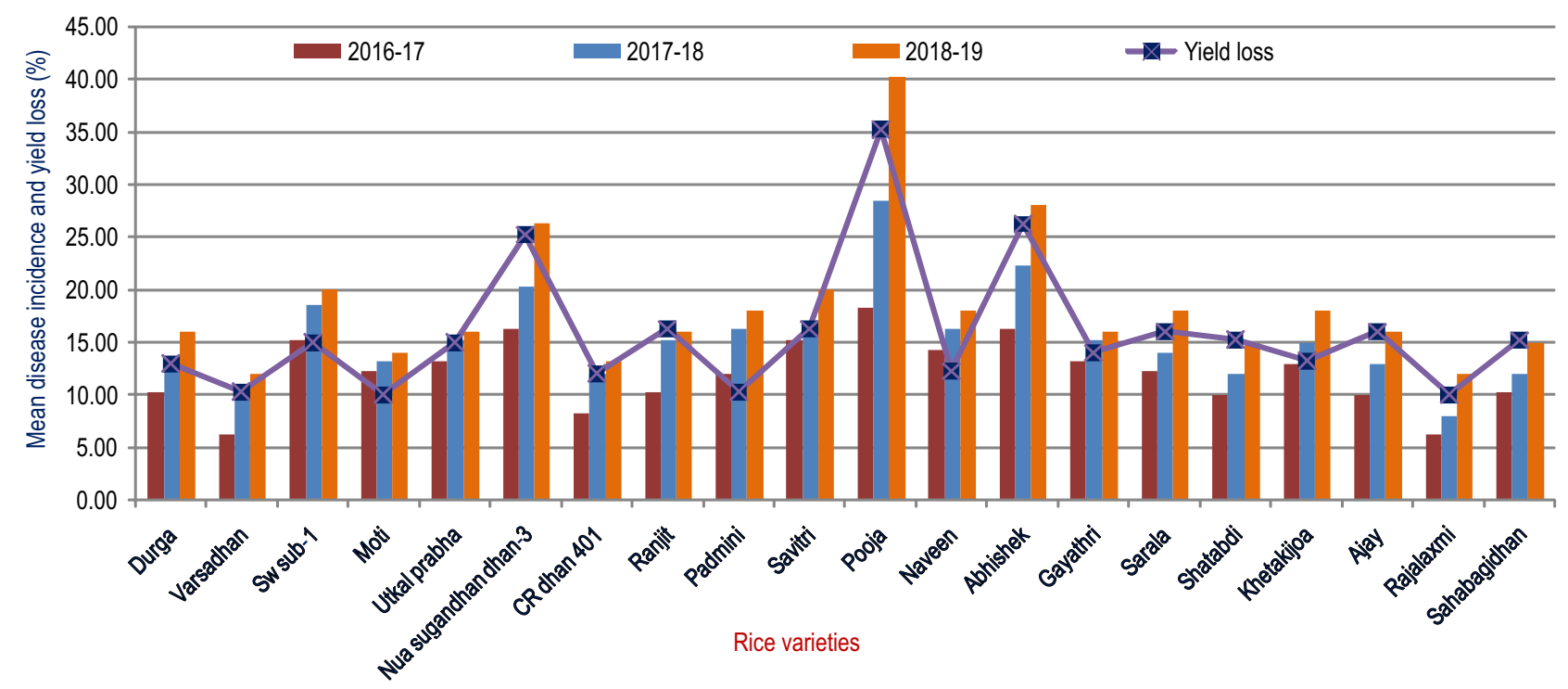

Fig. 1: Disease incidence and yield loss due to rice bakanae for three years in Odisha.

2012). The incidence of bakanae disease has increased steadily, particularly in aromatic rice cultivars in all rice growing states of India, which causes severe qualitative and quantitative yield losses to rice crop (Bashyal et al., 2014; Gupta et al., 2014).

The research on role of weather parameters on disease incidence is to be known before formulating management measures. Initially, we had estimated disease incidence for three consecutive years, 2016 to 2018 . Our observations suggested that, the maximum disease incidence and loss was reported from variety Pooja which is a popular variety in Eastern India, followed by Abhishek and Nua sugh and dhan-3. Our observations clearly indicated that the disease can affect both basmati and nonbasmati varieties. Several researchers have also estimated yield losses in different rice growing regions (Ahangar et al., 2014); Hossain et al., 2015). Gupta et al. (2015) reported that, the disease is responsible for high yield loss ranging from 3-95.4\% depending on varieties affected. Significantly large amount of yield loss was also reported from several Asian countries with approximately $20 \%$ yield loss in epidemic areas with worst infected countries like Japan, Taiwan, Turkey, California and Philippines (Cumagaun et al., 2011).

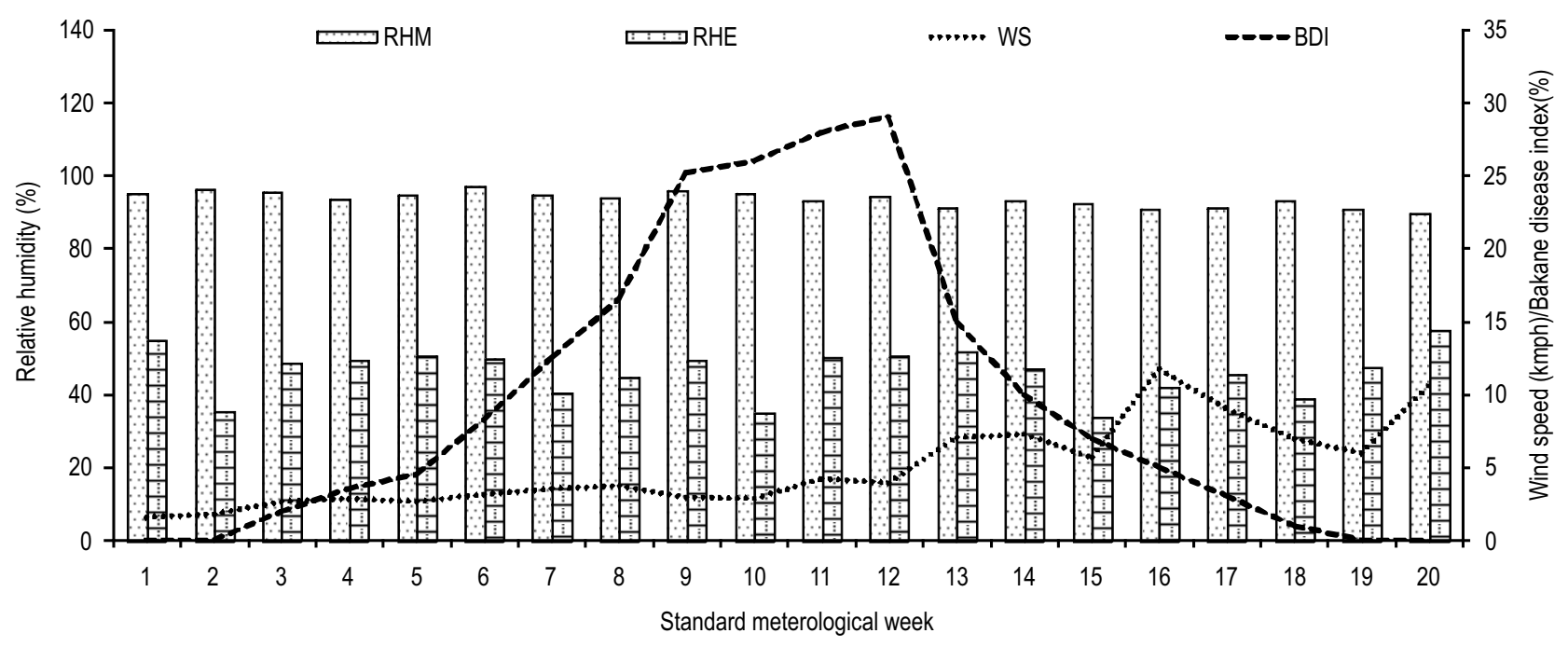

Fig. 2 A: Prevalence of bakanae disesase with influence of weather parameters (Year 2016-17). 


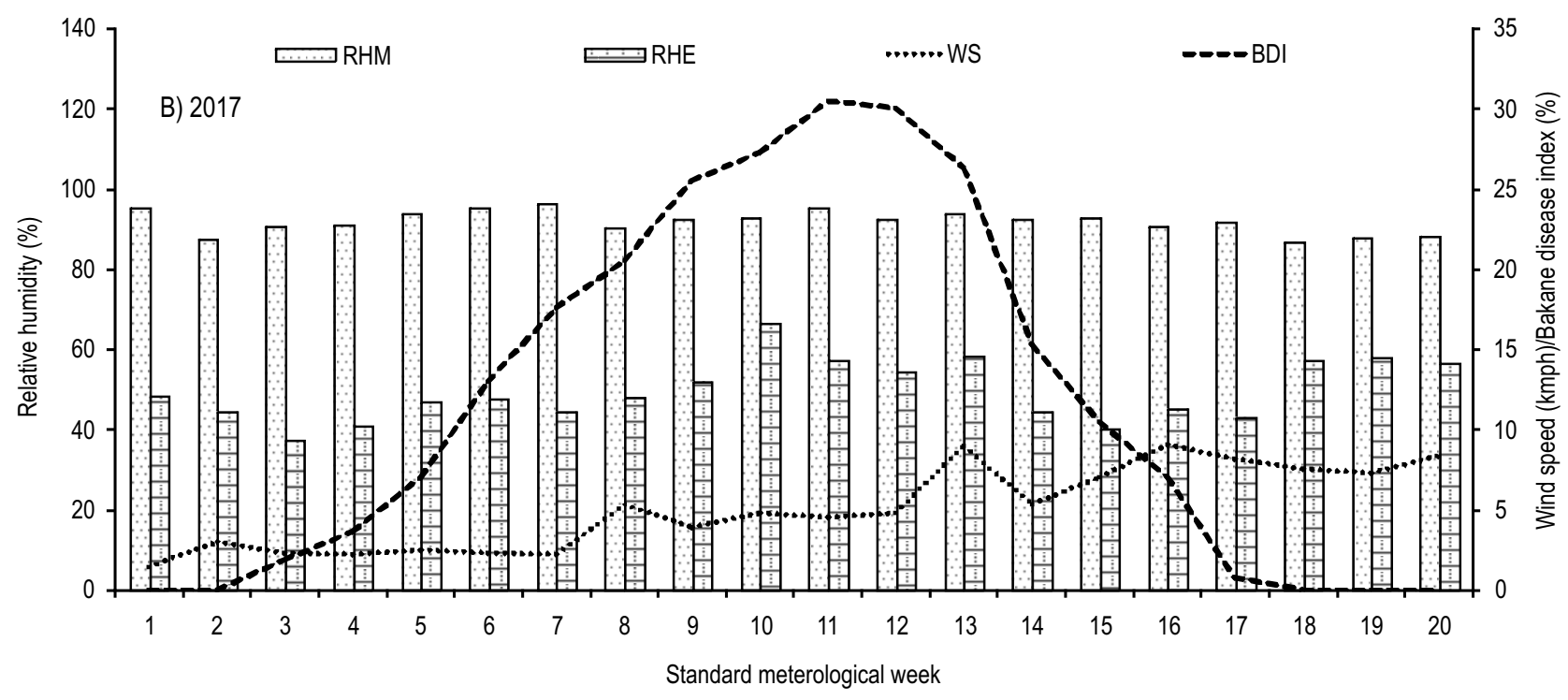

Fig. 2 B: Prevalence of bakanae disesase with influence of weather parameters (Year 2017-18).

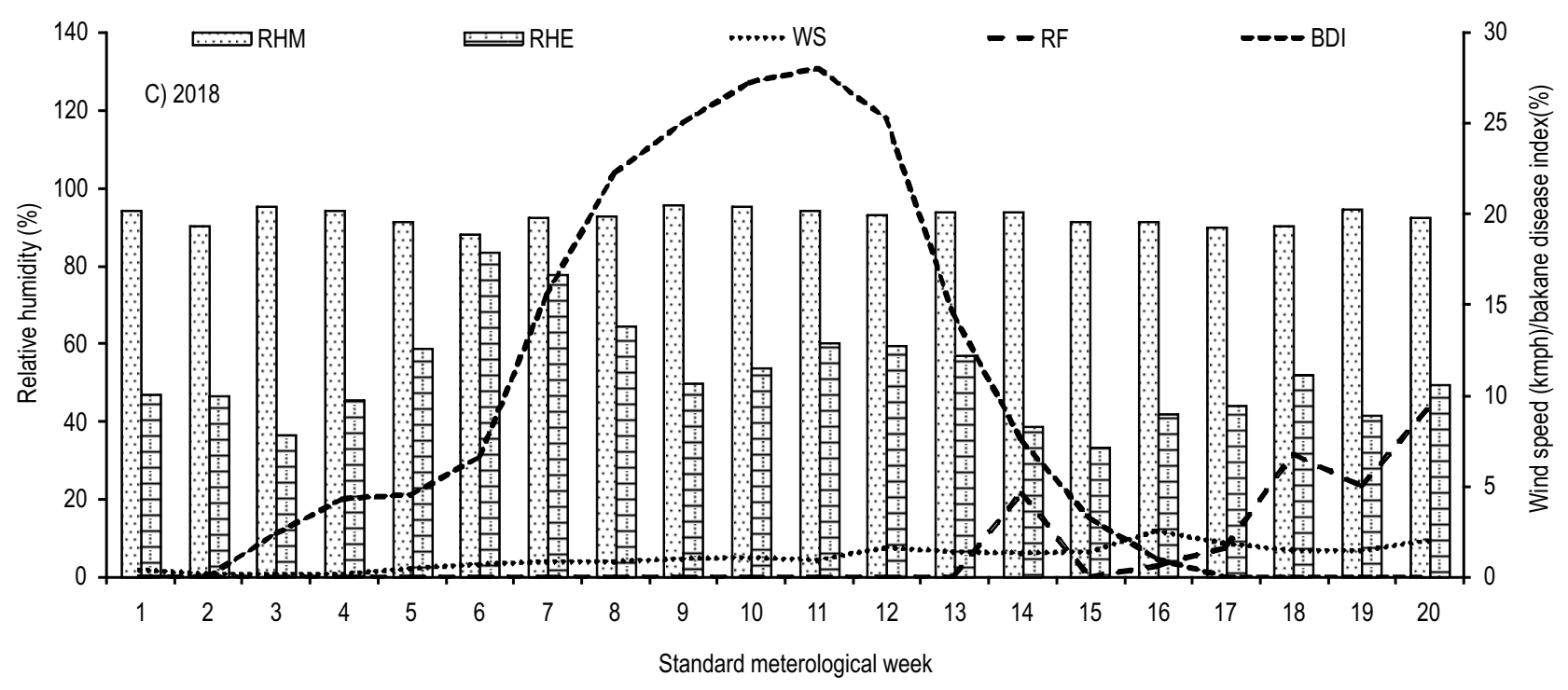

Fig. 2 C: Prevalence of bakanae disesase with influence of weather parameters (Year 2018-19).

All these observations clearly indicate that the disease is spreading rapidly in all the major rice production areas along with the threat of significant yield and quality losses. Very little work has been done on the epidemiological aspect of rice bakanae disease in relation to environmental conditions. It is necessary to understand the relationship between host, pathogen and environmental relationship in bakanae disease in order to manage the disease. Weather influences all stages of host and pathogen life cycles as well as the development of disease. Relationships between weather and disease are routinely used for forecasting and managing epidemics diseases.
Similar to the present study, Saremi and Farroki (2004) reported that high temperature and high relative humidity will favor the bakanae disease greatly in the transplanted rice plants than those of direct seeded plants. Some of the recent studies have reported that the effect of climate, especially rainfall and temperature significantly influences the disease development and pathogen population (Burgess et al., 1996; Saremi and Farraokhi, 2004) which was concordance with the results of this study. Wind acts as a carried of conidia of pathogen easily from one plant to another. Excess soil moisture increases pathogen population. Chan et al. (2004) reported positive correlation 
between disease incidence and soaking ( $r=0.8757)$ and sprouting $(r=0.9570)$ temperature at $28-34^{\circ} \mathrm{C}$. The present study clearly exhibited that previous week weather clearly contributing more to the disease growth and spread than the corresponding week weather parameters. Bakanae disease required an average of 12-16 days to produce the characteristic symptom (Bashyal et al., 2014) which is clearly visible from the results of this study that lag weeks relative humidity favored disease growth and spread. Seed-borne inoculum plays a major role in secondary transmission of disease under favorable environmental conditions by producing numerous conidia and infects fresh plant (Rosales and Mew, 1997). Fungus infects rice grains during flowering in field and carried along with seeds to storage also. Under storage conditions the pathogen multiplies and increases in population. The contaminated seeds after sowing in field results in disease incidence due to colonization in seedlings (Chung et al., 2016).

Based on the quantity of inoculums and environmental conditions, symptoms like abnormal seedling elongation, lanky and pale green plants, larger intermodal length, and roots produced from each node, growth of fungal mass on each node, production of chaffy or sterile panicles are found (Amatulli et al., 2010; Wulf et al., 2010; Jeon et al., 2013). In this, study temperature had negative correlation and relative humidity had positive correlation with bakanae disease incidence. Few researchers found opposite observations to present results, Yu and Sun (1976) recorded the importance of air borne ascospores in contaminating seeds during panicle initiation stage. Ascospores discharged into air during night or rain infect healthy panicle. The same workers also found that, under low relative humidity conditions, the ascospores oozes out from the ostioles and travel through air and initiates fresh infection. In Japan, average embryo infection of $8.8 \%$ was recorded July, $8.1 \%$ in August and only $0.03 \%$ during September as reported by Hino and Furuta (1968). This clearly indicates that high temperature is essential for disease infection. Likewise rice blast also temperature and disease severity was found to be negatively correlated which indicated that the disease increased with the decrease of temperature, whereas maximum relative humidity favored the disease development and spread (Pal et al., 2017) Shafaullah et al. (2011) also indicated that blast disease incidence increases with the decrease in temperature.

The latest research on role of weather parameters on bakanae disease incidence and losses are not yet studied/published. But the role of weather parameters on other rice diseases like blast, sheath blight and bacterial leaf blight are studied extensively by several workers.

In rice blast, the disease is more severe during the periods of cool temperature and high moisture (relative humidity), but the conidia of the fungus will not germinate under direct sun light (1985). Jeyanadarajah and Seveviratnae (1991) reported that cloudy overcast weather and dew encourages blast spread. Pathogen conidia remains viable during winter even under snow and causes fresh infection during subsequent seasons. Prasad et al. (2015) conducted an experiment from1984-2012 in Himachal Pradesh revealed that days with minimum temperature $(\leq 20 \circ \mathrm{C})$ rainfall and cloud cover were important for appearance and progress of disease. Period of low temperature $\left(19.1^{\circ} \mathrm{C}\right)$ more number of days with minimum temperature of $\leq 20^{\circ} \mathrm{C}$ ( 11 days) and lower rainfall $(246.6 \mathrm{~mm}$ ) and more cloud amount (135 hrs) Similarly, Kapoor and Kundal (2007) reported that, mean maximum and mean minimum temperatures, mean morning and evening relative humidity, and rainy days per week are critical for disease development in mid hills of Himachal Pradesh.Similarly, Lenka et al. (2008) observed significant relation between maximum temperature, minimum temperature and rate of evaporation with that of per cent disease incidence of sheath blight (PDI). The prediction equation developed for PDI was $Y=$ 16.71+ 0.72 Max. Temperature.-1.14 Min. Temperature-1.86 Evaporation ( $R 2=0.931)$. Rice being a principal food crop is infected by a number of diseases. Many major diseases causing much more damage than earlier and much minor disease emerging as major problems. Hence it can be concluded from our experimental results that out of the weather parameters checked with bakanae disease relative humidity, rain fall and wind speed found as critical weather parameters for bakanae disease incidence at field condition at eastern India. However still more epidemiological studies are required to strengthen the forecasting and prediction mechanism of the disease which will ultimately minimize the yield losses caused by the disease.

Rice bakanae is emerging as one of the major problem in rice farming. Earlier, the disease was reported to cause damage only in basmati rice varieties. But our study found that, the disease can cause serious damage even in non basmati rice varieties. The disease is emerging as major problem in eastern India since last 5-6 years. This is mainly because of changing climatic conditions, cropping system and monocropping of same varieties. A clear understanding the role of weather parameters on disease incidence and the host-pathogen interactions under changing climatic conditions should be studied in detail.

\section{Acknowledgment}

The author thank the Director, ICAR-National Rice Research Institute, Cuttack, Odisha for his support and facilities provided. The work was not funded by any externally funded projects.

\section{Add-on Information}

Authors' contribution: S. Raghu: Conceptualization, Methodology, Excecution of the work, Original Writing, G. GuruPirasanna-Pandi: Conceptualization, Methodology, formal analysis, Investigation, M.S. Baite, M.K. Yadav, U. Keerthana: Resources, visualization, Writing, review and editing, S.R. Prabhukarthikeyan: Investigation, Resources, visualization, Writing \pm review \& editing, P.C. Rath: Resources, visualization, Writing \pm review \& editing, overall supervision. 
Research content: The research content of manuscript is original and has not been published elsewhere.

\section{Ethical approval: NotApplicable}

Conflict of interest: The authors declare that there is no conflict of interest.

\section{Data from other sources: NotApplicable}

Consent to publish: All authors agree to publish the paper in Journal of Environmental Biology.

\section{References}

Ahangar, M.A., Z.A. Bhat., S. Nazeeb., A. L. Zahoor and S.H. Dar: Bakanae Disease: Anew threat to rice production under temperate ecology of Kashmir. J. Agric. Life Sci.,1, 2375-4214 (2014).

Amatulli, MT., D. Spadaro, M.L. Gullino and A. Garibaldi: Molecular identification of Fusarium spp. associated with bakanae disease of rice in Italy and assessment of their pathogenicity. Plant Pathol., 59, 839-844 (2010).

Bal, R.S. and B. Biswas: Epidemiology and management of foot rot in Basmati rice. J. Krishi Vigyan, 6, 87-94 (2018)

Bashyal, B.M., R. Aggarwal, S. Sharma, S. Gupta, K. Rawat, D. Singh, A.K. Singh and S. Gopalakrishnan: Occurrence, identification and pathogenicity of Fusarium species associated with bakanae disease of basmati rice in India. Eur. J. Plant Pathol., 144, 457-466 (2014).

Bashyal, B.M.: Etiology of an emerging disease: Bakanae of rice. Indian Phytopathol., 71, 485-494 (2020).

Burgess, L.W., D. Backhouse, L.J. Swan and R.J. Esdaile: Control of Fusarium crown rot of wheat by late stubble burning and rotation with sorghum. Aust. Plant Pathol., 25, 229-233 (1996)

Chan, Z.L., K.J. Ding, G.J. Tan, S.J. Zhu, Q. Chen, X.Y. Su, K. Ma and A. E. Wang: Epidemic regularity of rice bakanae disease. J. Anhui. Agril. Univ., 31, 139-42 (2004)

Chung, L.N., K.J. Huang, S.Y. Chen, M.H. Lai, Y.C. Chen and Y.F. Kuo: Detecting Bakanae disease in rice seedlings by machine vision. Comp. Electro. Agricul., 121, 404-411 (2016).

Cumagun, C.J.R., E. Arcillas and E. Gergon: UP- PCR analysis of the seedborne pathogen Fusarium fujikuroi causing bakanae disease in rice. Int. J. Agric. Biol., 13, 1029-1032 (2011).

Fiyaz, R.A., S. Gopalakrishnan, H. Rajashekara, A.K. Yadav, Krishnan, B.M.Bashyal, P.K. Bhowmik,N.K. Singh, K.V. Prabhu and A.K. Singh: Development of high throughput screening protocol and identifcation of novel sources of resistance against bakanae disease in rice (Oryza sativa L.). Indian J.Genet., 74, 414-422 (2014).

Gupta, A.K., I.S. Solanki, B.M. Bashyal, Y. Singh and K. Srivatsava: Bakanae of rice -an emerging disease in asia. J. Ani. Plant Sci., 25, 1499-1514 (2015).

Hino, T. and T. Furuta: Studies on the control of bakanae disease of the rice plant caused by Gibberella fujikuroi. 2. Influence of flowering season of rice plant on seed susceptibility trough flower infection. Bull. Chugoku-ShikokuAgricul. Experim. Stat., 2, 97-102(1968).

Hossain, K.S., M. Mat and M. Bashar: Management of bakanae disease of rice. Bangladesh J. Bot., 44, 277-283 (2015).

Jain, S.K., K. Khilari, M. Dongre and S. Pal: Occurrence of Bakanae disease of rice in Western Uttar Pradesh, India. Int. J. Curr. Microbiol. App. Sci., 8, 207-212 (2019).

Jena, M., G.P.P. Pandi, T. Adak, P.C. Rath, B. Gowda, N.K.B. Patil, G.
Prasanthi and S.D. Mohapatra: Paradigm shift of insect pests in rice ecosystem and their management strategy. Oryza Int. J. Rice, 55, 82-89 (2018)

Jeon, Y.A., S.H. Yu, Y.Y. Lee, H.J. Park, S. Lee, J.S. Sung, Y.G. Kim and H. S. Lee: Incidence, molecular characteristics and pathogenicity of Gibberella fujikuroi species complex associated with rice seeds from Asian countries. Mycrobiology, 41, 225-233 (2013).

Jeyanandarajah, P. and S.N.D.S. Seveviratne: Fungi seed-borne in rice (Oryza sativa) in Sri Lanka. Seed Sci Tech., 19, 561-569(1991)

Kapoor, A.S and R. Kaundal: Development of weather based forewarning systems for rice blast. Him. J. Agri. Res., 33, 211-217 (2007).

Khush, G.S.: What it will take to feed 5.0 billion rice consumers in 2030 ? Plant Mol. Biol., 59,1-6 (2005).

Lenka, S., S.K. Mishra, S.K. Mohanthy and S. Saha: Role of weather parameters on sheath blight incidence in rice caused by Rhizoctonia solani, Kuhn. Oryza, 45, 336-338 (2008)

Luo, Y., P.S. Teng, N.G. Fabellar and D.O.T. Beest: Risk analysis of yield losses caused by rice leaf blast associated with temperature above and below for five Asian countries. Agric. Ecos. Environ., 68, 197-205(1988).

Matic, S.M.L. Gullino and D. Spadaro: The puzzle of bakanae disease through interactions between Fusarium fujikuroi and rice. Front. Bioci. Elite Ed., 9, 333-344 (2017).

Pal, R., D. Mandal and B.S. Naik: Effect of different meteorological parameters on the development and progression of rice leaf blast disease in western Odisha. Int. J. Plant Protec., 10, $52-57$ (2017).

Pannu, P.P.S., J. Kaur, G. Singh and J. Kaur: Survival of Fusarium moniliforme causing foot rot of rice and its virulence on different genotypes of rice and basmati rice. Ind. Phytopath., 65, 149-209 (2012).

Prasad, R., A. Sharma and S. Sehgal: Influence of weather parameters on occurrence of rice blast in mid hills of Himachal Pradesh. Himachal. J. Agr. Res., 41, 132-136 (2015).

Raghu, S., M.K. Yadav, S.R. Prabhukarthikeyan, M.S. Baite, S. Lenka and J. Jena: Occurrence pathogenicity characterization of Fusarium fujikuroi causing rice bakanae disease from Odisha and in-vitro management. Oryza, 55, 214-223 (2018).

Raghu, S., S. Lenka, M.S. Baite, M.K. Bag and M. Jena: Rice Bakanae/ foot rot. an emerging threat to rice production in Odisha. NRRI Newsletter, 37, 17-18 (2016).

Rosales, A.M and T.W. Mew: Suppression of Fusarium moniliforme in rice by rice-associated antagonistic bacteria. Plant Dis., 81, 49-52 (1997).

Saremi, $\mathrm{H}$ and F. Farrokhi: Study on bakanae disease of rice and evaluation of cultivars in Gilan and Zanjan provinces Iran. Proc. Fourth Int. Iran and Russia Conf., pp. 358-364 (2004).

Shafaullah, M.A., Khan N.A. Khan and Y. Mahmood: Effect of epidemiological factors on the incidence of paddy blast (Pyricularia oryzae) disease. Pak. J. Phytopathol., 23, 108-111 (2011).

Sunder, S., R. Singh and D.S. Dodan: Management of bakanae disease of rice caused by Fusarium moniliforme. Ind. J. Agril. Sci., 84, 224$228(2014)$

Wulff, E.G., J.L. Sørensen, M. Lübeck, K.F. Nielsen, U. Thrane and J. Torp: Fusarium spp. associated with rice Bakanae: Ecology, genetic diversity, pathogenicity and toxigenicity. Environ. Microbiol., 12, 649-657 (2010).

Yu, K.S. and S.K. Sun: Ascospore liberation of Gibberella fujikuroi and its contamination of rice grains. Plant Prot. Bull., 18, 319-329 (1976).

Zainudin, N.A.I.M., A. A. Razak and B. Salleh: Bakanae disease of rice in Malaysia and Indonesia: Etiology of the causal agent based on morphological, physiological and pathogenicity characteristics. J. Plant Prot. Res., 48, 4 (2008). 